\title{
Biological synthesis and characterization of silver nanoparticles using Eclipta alba leaf extract and evaluation of its cytotoxic and antimicrobial potential
}

\author{
PARAMASIVAM PREMASUDHA ${ }^{1}$, MUDILI VENKATARAMANA ${ }^{2, *}$, MARRIAPPAN ABIRAMI ${ }^{3}$, \\ PERIYASAMY VANATHI ${ }^{4}$, KADIRVELU KRISHNA ${ }^{2}$ and RAMASAMY RAJENDRAN ${ }^{3}$ \\ ${ }^{1}$ Department of Nanoscience and Technology, Bharathiar University, Coimbatore 641 046, India \\ ${ }^{2}$ DRDO-BU CLS, Bharathiar University Campus, Coimbatore 641 046, India \\ ${ }^{3}$ Department of Microbiology, PSG College of Arts and Science, Coimbatore 641 014, India \\ ${ }^{4}$ Department of Microbiology, Maharaja Co-education College, Perundurai 638 052, India
}

MS received 5 February 2015; accepted 3 March 2015

\begin{abstract}
With increasing global competitions there is a growing need to develop environmentally benevolent nanoparticles without the use of toxic chemicals. The biosynthesis of silver nanoparticles (AgNPs) using plant extracts became one of the potential areas of research. The bioreduction of metal ion is quite rapid, readily perform at room temperature and easily scale up. The present study describes a rapid and eco-friendly synthesis of AgNPs using Eclipta alba plant extract in a single pot process. The efficiency and the influence of various process variables in the biosynthesis of AgNPs analysed include redundant concentration, temperature and time. AgNPs were rapidly synthesized using aqueous leaf extract of $E$. alba and was observed when the medium turned to brown colour with the addition of silver ion. Biosynthesized AgNPs were characterized by the help of UV-visible spectroscopy for their stability and physicochemical parameters were studied by dynamic light scattering, Fourier transform infrared spectroscopy, X-ray diffraction, scanning electron microscopy. The obtained results confirmed that recorded UV spectra show the characteristic surface plasmon resonance band for AgNPs in the range of 400-440 nm and physiochemical structural analysis shown that obtained AgNPs were crystalline in nature. Further, cytotoxic and antimicrobial activities of biosynthesized AgNPs against RAW 254.7, MCF-7 and Caco-2 cells as well as Gram positive and Gram negative bacteria were assessed. In-vitro cytotoxicity activity of characterized AgNPs against tested cell lines showed significant anti-cell-proliferation effect in nanomolar concentrations. The antibacterial activity of synthesized AgNPs showed effective inhibitory activity against human pathogens, including, Escherichia coli, Staphylococcus aureus and Pseudomonas aeruginosa. Thus, the significant outcome of this study would help to formulate value added herbal-based nano-materials in biomedical and nanotechnology industries.
\end{abstract}

Keywords. Eclipta alba; silver nanoparticles; cytotoxicity; antimicrobial activity.

\section{Introduction}

Nanotechnology is being used in diverse areas like chemistry, biology, catalysis, medicine, photonics, electronics, bio-labelling and information storage. ${ }^{1}$ Due to their unique physicochemical characteristics of nanoparticles, including catalytic activity, ${ }^{2}$ optical and electronic properties ${ }^{3,4}$ as well as cytotoxic and antimicrobial properties ${ }^{5}$ in recent year's scientists showed gaining interest towards the development of novel methods for synthesis of nanoparticles. Nanoparticles comprising of one or more dimensions with $100 \mathrm{~nm}$ or less have engrossed great attention due to their unusual and captivating properties. ${ }^{6,7}$ Silver was recognized as a disinfecting agent; in its nanoparticle forms induce their ability in functions from medicine to culinary items. ${ }^{8}$ Human beings are frequently infected by microorganisms such as

\footnotetext{
*Author for correspondence (ramana.micro@gmail.com)
}

bacteria, yeast, mold, virus, etc. Silver and silver ion-based materials are usually used for their bactericidal and fungicidal activities. ${ }^{9}$ Their antimicrobial effect is appropriate to blockage of respiratory enzyme pathways, interacting with the sulphur-containing proteins and modification of microbial DNA. ${ }^{10,11}$ The antimicrobial activity of silver is much superior to other metals, such as mercury, copper, lead, chromium and tin. ${ }^{12}$ Hence, silver and silver ion-containing materials are used as prostheses, catheters, vascular grafts and as wound dressings in several biomedical applications. ${ }^{2,3}$ As a result, the usage of silver-based viable products including topical ointments, bandages, augmentation devices; tissue scaffolds, antimicrobial filters, water purification systems and gels have been used in improving the public health care. $^{13,14}$

Various methods, including physical and chemical methods were developed to synthesize metal nanoparticles, such as chemical reduction, ${ }^{15}$ electrochemical reduction, ${ }^{16}$ photochemical reduction, ${ }^{17}$ etc. Nanoparticles have a tendency 
to aggregate in most cases, surface passivator reagents are needed to prevent aggregation. ${ }^{18}$ Unluckily many of these organic passivators like thiourea ${ }^{19}$ and mercaptoacetate ${ }^{20}$ are toxic to the environment when used in large quantities. In contrast to the chemical and physical methods, biological method of nanoparticles synthesis using microorganisms, enzyme and plant or plant extract offers numerous benefits to offer a valuable contribution as eco-friendly technologies into nano-material science. ${ }^{21}$ On the other hand, biological methods are free from the use of toxic solvents for synthesis of nanoparticles which are hazardous to the environment. ${ }^{18}$ The utility of plant-based phytochemicals in the overall synthesis and architecture of nanoparticles and various nanoparticles embedded products is highly attractive as it brings an important symbiosis between natural/plant sciences and nanotechnology. This connection between plant sciences and nanotechnology provides an inherently green approach to nanotechnology referred to as green nanotechnology. ${ }^{22}$ Among the various known biosynthesis methods, plant-mediated nanoparticle synthesis is preferred as it is cost-effective, eco-friendly and safe for human therapeutic applications. Many reports are available on the biogenesis of AgNPs using several plant extracts, particularly Lantana camara, Moringa oleifera, Catharanthus roseus, Eucalyptus hybrid, Cassia auriculata. ${ }^{23}$ However, potential of the plants as biological materials for the synthesis of nanoparticles is still under exploitation.

In the present study, we developed an optimized method for syntheses of silver nanoparticles (AgNPs) using aqueous leaf extracts of E. alba. Various reaction conditions were optimized to obtain mono-dispersed AgNPs and were characterized using ultraviolet (UV), dynamic light scattering (DLS), Fourier transform infrared (FTIR) spectroscopy, X-ray diffraction (XRD) and scanning electron microscopy (SEM) imaging. Cytotoxic and antimicrobial activities of biosynthesized AgNPs were evaluated against RAW 254.7, MCF-7 and Caco-2 cells as well as Gram positive and Gram negative bacteria to reveal the functional utility of synthesized AgNPs in biomedical applications.

\section{Materials and methods}

\subsection{Materials}

The fresh leaves of E. alba were collected from Western Ghats, India. Silver nitrate $\left(\mathrm{AgNO}_{3}\right)$, Muller Hinton Agar (MHA), nutrient broth, MTT (methyl thiozolyldiphenyltetrazolium bromide) were purchased from Himedia Laboratories Pvt. Ltd., Mumbai, India. The bacterial cultures of Escherichia coli (MTCC-1652), Staphylococcus aureus (MTCC-96) was obtained from Microbial Type Culture Collection, Chandigarh, India and pathogenic cultures of Pseudomonas aeruginosa were obtained from Kovai Medical Centre and Hospital, Coimbatore, India.

\subsection{Methods}

2.2a Preparation plant extract and biosynthesis of AgNPs: To improve the reproducibility of the investigational results and to optimize the biosynthesis method as a complete, the factorial aim of research, the 'one factor-at-a time' method, was utilized in this study. Now, the investigational features are diverse one at an occasion among the residual factors held stable. The leaf extract was prepared using freshly collected leaves of E. alba. They were surface cleaned thoroughly with running tap water, followed by distilled water. Then the leaves were cut into small pieces and boiled with sterile deionized water $\left(\mathrm{ddH}_{2} \mathrm{O}\right)$ at $60^{\circ} \mathrm{C}$ for $5 \mathrm{~min}$. The prepared leaf extract was filtered through Whatman No. 1 filter paper to attain clear solution and was used to synthesize AgNPs. Biological reduction of $\mathrm{AgNO}_{3}$ was carried out initially as follows: $1 \mathrm{mM} \mathrm{AgNO}_{3}$ solution was added to different concentrations of plant extract including $1: 3,1: 4,1: 5,1: 7$ (1:9 for example $1: 9$ ratio-1 part of $10 \%$ extract and 9 parts of sterile $\mathrm{ddH}_{2} \mathrm{O}$ and incubated for $30 \mathrm{~min}$ in rotary shaker at $110 \mathrm{rpm}$ at $37^{\circ} \mathrm{C}$. To observe the kinetics of the AgNPs biosynthesis, in order to obtain the monodispersed and uniform sized AgNPs, several parameter reaction conditions were optimized including E. alba aqueous extract (10\%), time (20-24 min) and temperatures $\left(28,32,37,45\right.$ and $\left.60^{\circ} \mathrm{C}\right)$ to $1 \mathrm{mM} \mathrm{AgNO}_{3}$ solution.

$2.2 \mathrm{~b}$ Separation and purification of AgNPs from crude matrix: The AgNPs were separated by centrifugation at $10,000 \mathrm{rpm}$ for $15 \mathrm{~min}$ to dispose some of unwanted biological molecules; subsequently the pellet was redispersed in sterile $\mathrm{ddH}_{2} \mathrm{O}$. The purification of nanoparticles by centrifugation and re-dispersion in sterile $\mathrm{ddH}_{2} \mathrm{O}$ was constantly carried out to ensure the better elimination of free entities. The purified pellet was freeze dried and lyophilized using a lyophilizer.

2.2c Characterization of nanoparticles: UV-vis spectroscopy: The formation of AgNPs was primarily observed by monitoring the change in colour of the extract after treated with $\mathrm{AgNO}_{3}(1 \mathrm{mM})$. The bio-reduction of $\mathrm{Ag}$ ions in aqueous extract was monitored with the UV-visible spectra of the solutions after diluted a small aliquot $(0.1 \mathrm{ml})$ of the sample to 10 times with $\mathrm{ddH}_{2} \mathrm{O}$. UV-visible spectra were recorded with Hitachi double beam spectrophotometer (Hitachi, Japan) from 300 to $700 \mathrm{~nm}$ wavelength at room temperature. Double distilled water was used as reaction blank.

$D L S$ : Size distribution and zeta potential of bio-reduced AgNPs were measured using DLS (Zetasizer Nano ZS, ZEN3600 and Malvern, UK). The mean size and its zeta potential of the particles were obtained.

FT-IR: Crude AgNPs were purified and washed with $\mathrm{ddH}_{2} \mathrm{O}$ three times and dried. After drying AgNPs were grinded with $\mathrm{KBr}$ pellets and were subjected to FT-IR 
spectroscopy in the range of $450-4000 \mathrm{~cm}^{-1}$ at a resolution of $4 \mathrm{~cm}^{-1}$.

XRD measurements: XRD analysis of the biologically synthesized AgNPs cast onto glass slides were done as per the previous report of Singhal et al. ${ }^{9}$ Briefly, PAN ANALYTICAL X-ray diffractometer machine operating at a voltage of $40 \mathrm{kV}$ and current of $20 \mathrm{~mA}$ with $\mathrm{Cu} \mathrm{K}(\alpha)$ radiation of $1.54187 \mathrm{~nm}$ wavelength. The scanning as carried out with $2 \theta$ angle from $20^{\circ}$ to $80^{\circ}$ at $0.02 \mathrm{deg} \mathrm{min}^{-1}$, with $2 \theta$ time constant.

SEM: SEM experiments were performed to characterize size and shape of bio-reduced AgNPs. Purified AgNPs were sonicated for $15 \mathrm{~min}$ to make it uniform distribution and a drop of this solution was loaded on carbon-coated copper grids and solvent was allowed to evaporate under infrared light for $30 \mathrm{~min}$. SEM measurements were performed on Icon Analytical, FEI Quanta 200.

2.2d In-vitro cytotoxic potential of AgNPs: MTT assay: Cell viability and IC50 values of the compounds were determined by MTT assay. ${ }^{24}$ Briefly, RAW 254.7, MCF-7 and Caco- 2 cells $\left(5 \times 10^{3}\right)$ were seeded into individual 96-well plates and incubated at humidified environment with $5 \% \mathrm{CO}_{2}$ at $37^{\circ} \mathrm{C}$. After $24 \mathrm{~h}$ of incubation, cells were treated with different concentrations of AgNPs ranging from 0 to $1000 \mathrm{ng}$. After $48 \mathrm{~h}$ of incubation media was removed and $10 \mu \mathrm{l}$ of MTT $\left(5 \mathrm{mg} \mathrm{ml}^{-1}\right)$ dye was added along with $90 \mu \mathrm{l}$ of serumfree medium and incubated at $37^{\circ} \mathrm{C}$. Four hours later the medium containing MTT was aspirated and replaced by solubilization solution DMSO for $30 \mathrm{~min}$. Following this incubation, the absorbance was measured in an ELISA reader at $570 \mathrm{~nm}$. IC50 values were determined as per the previous reports. $^{24}$

2.2e Screening of antibacterial activity of AgNPs: The synthesized AgNPs of E. alba was tested for antibacterial activity by well diffusion method and minimum inhibitory concentration (MIC) against clinically isolated Gram positive and Gram negative microorganisms like $S$. aureus, E. coli and $P$. aeruoginosa. The pathogenic cultures were subculture into peptone broth and incubated at $37^{\circ} \mathrm{C}$ to attain $10^{5}-10^{6} \mathrm{CFU} \mathrm{ml}{ }^{-1}$ using MacFarland's standard and were used in further experiments.

Agar well-diffusion method: Muller Hinton Agar plates were swabbed with fresh cultures of pathogenic organisms using sterile cotton swab. Approximately 6-mm diameter of well was made with the help of sterile gel puncture. Using a micropipette, the synthesized AgNPs $\left(\mathrm{mg} \mathrm{ml}^{-1}\right)$ were loaded at different concentrations including 25, 50, 70 and $100 \mu \mathrm{l}$. Chloramphenicol was used as a positive control, followed by the plates was incubated at $37^{\circ} \mathrm{C}$ for $18-24 \mathrm{~h}$ to measure the zone of inhibition.

MIC: The MIC was determined by the microdilution method. The synthesized AgNPs was suspended in $d_{d d} \mathrm{H}_{2} \mathrm{O}$ water. The culture broths of the test organisms were diluted to contain approximately $10^{5}-10^{6} \mathrm{CFU} \mathrm{ml^{-1 }}$. The MIC was defined as the lowest concentration of the nanoparticles that inhibited the visual growth of the test cultures on the test tubes.

2.2f Statistical analysis: Data are expressed as mean \pm SE of a minimum of four replicates and all the experiments were repeated twice. Statistical differences between control and target groups for all experiments were determined using Student's $t$-test with two-way Anova was set at $p \leq 0.05$.

\section{Result and discussion}

\subsection{Syntheses of AgNPs: process optimization and $U V$ characterization}

In order to prepare mono-dispersed and uniform shaped AgNPs by bio-reduction methods different conditions were optimized including extract concentration, reaction time and temperature. Synthesis of metal nanoparticles using various plant extracts were reported previously. ${ }^{9,23}$ Based on these reports, initial reaction was carried out with a $10 \%$ extract concentration (W/V) of $100 \mathrm{ml}$ in deionized water was used for the reduction of silver ions ( $1 \mathrm{mM} \mathrm{AgNO}_{3}$ ) to nanoparticles. When the plant leaf extract of $E$. alba was subjected to $\mathrm{AgNO}_{3}$, the biosynthesis reaction started within few minutes and the colour reaction was observed visually in which clear $\mathrm{AgNO}_{3}$ solution changed into brown colour which indicates the formation of AgNPs (figure 1) as reported earlier. ${ }^{9,25}$ The formation of the reduced AgNPs ( $\lambda_{\text {maximum }}$ ) was observed by UV-visible spectrophotometer at 300-700 $\mathrm{nm}$ range. The UV-visible spectra showed distinct maximum absorbance at $433 \mathrm{~nm}$ and it was corresponding to the surface plasmon resonance (SPR) of AgNPs (figure 2). The absorption band of metal nanoparticles is conquered by the SPR, which displays a shift in the direction of the red end or blue end depending upon the particle size, shape, aggregation state and the adjacent dielectric medium. ${ }^{26}$

When the reaction was carried out with varied extract concentrations, time intervals and temperatures with constant $\mathrm{AgNO}_{3}(1 \mathrm{mM})$ concentration, the intensity of the colour varies with directly proportional to the extract concentration (figure 3a), reaction time (figure $3 b$ ) and reaction temperature (figure $3 \mathrm{c}$ ). In present study synthesized nanoparticles with different extract ratios $(\mathrm{W} / \mathrm{V})$ such as $1: 3,1$ : 4 and $1: 5$ to $1 \mathrm{mM} \mathrm{AgNO}_{3}$ observed very weak plasmon resonance band (absorbance value $0.31,0.32,0.53$ ) at 349 , $337,520 \mathrm{~nm}$, respectively. The presence of the minor and major absorption bands could have been due to polydispersity in the size or shape of the nanoparticles. Upon increasing the extract ratio to $1: 7$ and $1: 9, \lambda_{\text {maximum }}$ increased to 411 and $432 \mathrm{~nm}$, respectively, with an absorbance 1.08 and 1.09. On other hand, increasing the ratio to $1: 19$ a significant change in $\lambda_{\text {maximum }}$ to $457 \mathrm{~nm}$ was distinguished however absorbance declined to 0.769 . This could be explained 


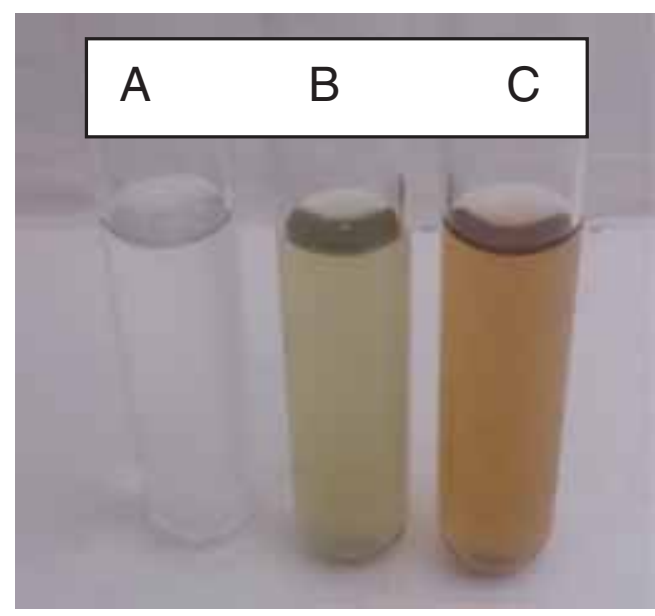

Figure 1. Synthesis of silver nanoparticles using aqueous extract of Eclipta alba: (A) silver nitrate $\left(\mathrm{AgNO}_{3}\right),(\mathrm{B})$ aqueous extract of E. alba and (C) aqueous extract with silver nitrate.

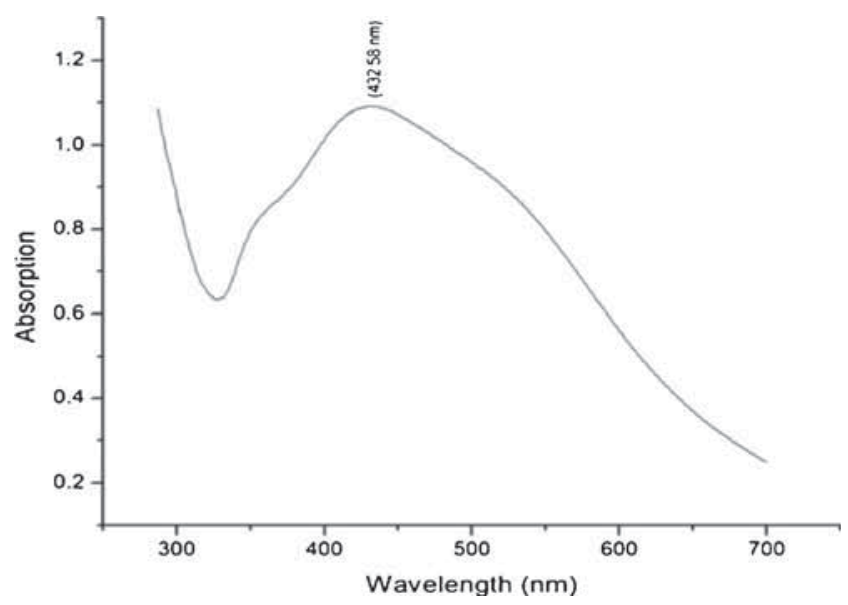

Figure 2. UV-visible spectra analysis of silver nanoparticles by E. alba.

by the reduction of silver ions to atoms by means of a reducing agent. The obtained atoms then nucleate in small clusters that grow into particles. Depending on the availability of atoms, which in turn depends on the silver salt to reducing agent concentration ratio, the size and shape of the nanoparticles can be controlled. ${ }^{27}$ In present study, the optimized extract concentration was determined as $1: 9(\mathrm{~W} / \mathrm{V})$ ratio of $10 \%$ E. alba extract in deionized water. Figure 3a shows the $1: 9(\mathrm{~W} / \mathrm{V})$ ratio of $\mathrm{UV}-\mathrm{visible}$ spectrum of the silver nanoparticles attained from diverse interaction time tests.

On the other hand, among the interaction time points studied from $30 \mathrm{~min}$ to $72 \mathrm{~h}, 24 \mathrm{~h}$ of incubation showed maximum intensity of the colour change and the change in $\lambda_{\text {maximum }}$ from 428 to $433 \mathrm{~nm}$ was observed. Upon increasing the interaction time up to $48 \mathrm{~h}$, the $\lambda_{\text {maximum value did not vary signif- }}$ icantly. The highest absorbance was observed at $24 \mathrm{~h}$ at 1.09 .
Further experiments were followed with this extract concentration. Among the studied temperatures $\left(28-60^{\circ} \mathrm{C}\right)$ on bioreduction of $\mathrm{AgNPs}, 32^{\circ} \mathrm{C}$ showed the significant increase in AgNPs formation. As shown in table 1, at this temperature the change in $\lambda_{\text {maximum }}$ to $433 \mathrm{~nm}$ was distinguished with an absorbance of 1.09. Table 1 represents the optimization of different reaction conditions.

\subsection{Characterization of AgNPs}

Several characterization techniques have been reported worldwide for the characterization of herbal and medicinal plants with silver-based nanoparticles which includes visual examination, UV-vis, FT-IR, DLS, XRD TEM and SEM analysis. ${ }^{9,28}$

3.2a UV-Vis spectral characterization: UV-vis characterization of bio-reduced AgNPs was followed as per the previous reports of Singhal et al. ${ }^{9}$ After the optimization of bio-reduction of $\mathrm{AgNO}_{3}$ to AgNPs in the presence of $E$. alba aqueous leaf extract UV spectral characterization was undertaken. UV spectral readings an! obtained $\lambda_{\text {maximum }}$ values indicated that the presence of AgNPs in the solution after the addition of extract (1:9) to $1 \mathrm{mM} \mathrm{AgNO}_{3}$ for $24 \mathrm{~h}$ reaction time with $32^{\circ} \mathrm{C}$ (figure 3 ). The present study results are in line with the previous reports of Singhal et al, ${ }^{9}$ Nayak et $\mathrm{l}^{18}$ and Kaler et $a l^{28}$ for the biosynthesis of AgNPs from cell-free extracts of microorganisms as well as plant extracts.

3.2b DLS analysis of particle size and zeta potential: The particle size analysis showed that the AgNPs synthesized in the bioreduction process using plant leaf extract were extensively distributed in the solution. The particle size of the AgNPs was approximately $422 \mathrm{~nm}$ and zeta potential of the nanoparticles was $34 \mathrm{mV}$ and it showed good stability (figure 4). The DLS measured size is slightly bigger as compared to the particle size measured from SEM micrographs, it could be explained by the DLS method which measures the hydrodynamic radius.

3.2c XRD characterization: The XRD pattern of biosynthesized AgNPs was confirmed by the characteristics peak observed in XRD image (figure 5). In the XRD pattern, four prominent diffraction peaks were observed at $2 \theta=$ $37.85^{\circ}, 44.0^{\circ}, 64.2^{\circ}$ and $77.2^{\circ}$, which correspond to (111), (200), (220) and (311) Bragg's reflections of the face-centred cubic (fcc) structure of metallic silver, respectively. Peaks observed in the pattern are well agreed with the previously reported values (JCPDS card no. 04-0783). The sharp as well as broad diffraction pattern infers that the synthesized system possess nanodimensional state. The multiple peaks possessed by the particles refer the multiple faceted growth orientation of the particles. ${ }^{29}$ It is also presumed that the 
(a)

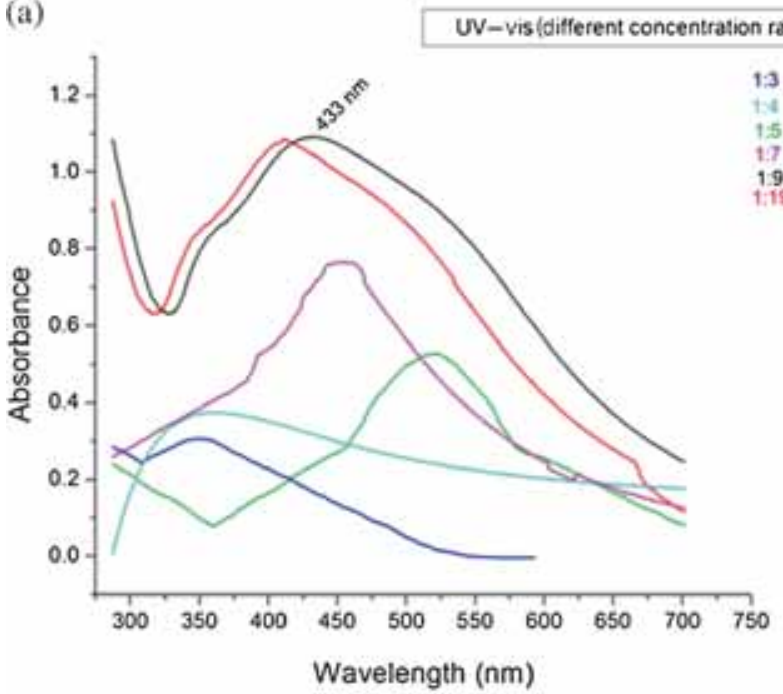

(b)

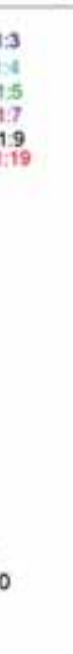

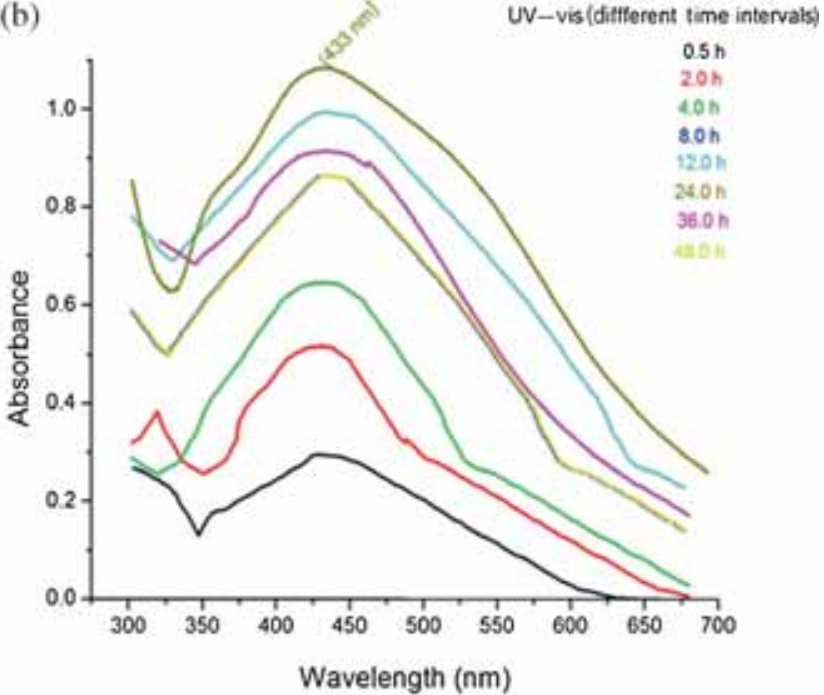

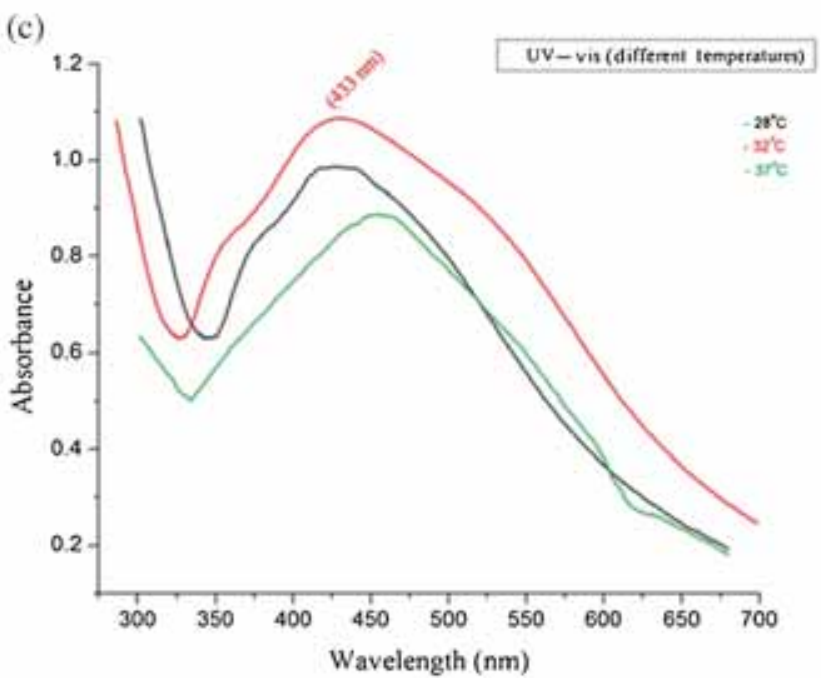

Figure 3. UV-visible spectra analysis of bioreduced silver nanoparticles syntheses optimization by E. alba. (a) UV-vis analysis of different concentration ratios, (b) different time intervals and (c) different temperatures.

broadness in the peak may also arise from the local crystal defects (elongational strain/compressional stress) in the nanocrystals.

3.2d FT-IR spectroscopy: FT-IR spectroscopic studies were carried out to find out possible bio-reducing agents present in the extract used (figure 6). It is confirmed the fact that to identify the bio-molecules for reduction and efficient stabilization of the metal nanoparticles, the band at 3603 and $3471 \mathrm{~cm}^{-1}$ of $\mathrm{O}-\mathrm{H}$ stretch as also the H-bonded shifted to 3541 and $3495 \mathrm{~cm}^{-1}$, alcohols and phenols. The peak at $3325 \mathrm{~cm}^{-1}$ of $\mathrm{N}-\mathrm{H}$ stretch shifted to 3379 and 3278 $\mathrm{cm}^{-1}$, indicating primary and secondary amines and amides. The band at $2931 \mathrm{~cm}^{-1}$ of $\mathrm{C}-\mathrm{H}$ stretch shifted to 2924 and 2854 corresponding to alkanes. The band at $2777 \mathrm{~cm}^{-1}$ of $\mathrm{C}-\mathrm{H}$ stretch represents aldehydes have only present in the plant leaf extract. The band at $2167 \mathrm{~cm}^{-1}$ corresponding to $-\mathrm{C} \equiv \mathrm{C}-$ stretching represents alkynes have both samples, while the peak at $1689 \mathrm{~cm}^{-1}$ stating $\mathrm{C}=\mathrm{O}$ represents carbonyl groups. The bands at $1527 \mathrm{~cm}^{-1}$ of asymmetric bond represents nitrocompound restrain in both samples. The bands at 1265 and $1180 \mathrm{~cm}^{-1}$ indicating the presence of $\mathrm{C}-\mathrm{H}$ stretching alkyl halides has shifted to 1172 and $1018 \mathrm{~cm}^{-1}$. The band at $1064 \mathrm{~cm}^{-1}$ corresponding to $\mathrm{C}-\mathrm{N}$ stretch represents aliphatic amines has only present in the plant leaf extract.

3.2e SEM image analysis: SEM analysis was used to measure the size and shape of the AgNPs formed and the images of the SEM visualization are shown in figure 5. Synthesized nanoparticles showed face centred cubic form and showed a large distribution of sized with ranging from 310 to $400 \mathrm{~nm}$. There was no visible agglomeration was observed between the nanoparticles (figure 7). 


\subsection{In-vitro cytotoxic potential of AgNPs}

In consideration with possible biomedical applications of AgNPs, in the present study was undertaken with different cancerous cell line models including RAW 264.7 (mouse macrophage cells), MCF-7 (human breast cancer cells) and

Table 1. UV-visible spectra of silver colloid solution produced under different conditions.

\begin{tabular}{|c|c|c|c|}
\hline S. no. & $\begin{array}{l}\text { Variable } \\
\text { conditions }\end{array}$ & $\begin{array}{l}\text { Wavelength } \\
\quad(\mathrm{nm})\end{array}$ & $\begin{array}{c}\text { Absorbance } \\
\left(\lambda_{\max }\right)\end{array}$ \\
\hline \multicolumn{4}{|c|}{ Effect of concentration $(\mathrm{ml})$} \\
\hline 1 & $1: 3$ & 349 & 0.31 \\
\hline 2 & $1: 4$ & 337 & 0.32 \\
\hline 3 & $1: 5$ & 520 & 0.53 \\
\hline 4 & $1: 7$ & 411 & 1.08 \\
\hline 5 & $1: 9$ & 433 & 1.09 \\
\hline 6 & $1: 19$ & 457 & 0.76 \\
\hline \multicolumn{4}{|c|}{ Effect of temperature $\left({ }^{\circ} \mathrm{C}\right)$} \\
\hline 7 & $28^{\circ} \mathrm{C}$ & 428 & 0.99 \\
\hline 8 & $32^{\circ} \mathrm{C}$ & 433 & 1.09 \\
\hline 9 & $37^{\circ} \mathrm{C}$ & 454 & 0.89 \\
\hline 10 & $45^{\circ} \mathrm{C}$ & ND & ND \\
\hline 11 & $60^{\circ} \mathrm{C}$ & ND & ND \\
\hline \multicolumn{4}{|c|}{ Effect of time intervals $(h)$} \\
\hline 12 & 0.5 & 428 & 0.29 \\
\hline 13 & 1.0 & 428 & 0.4 \\
\hline 14 & 2.0 & 430 & 0.52 \\
\hline 15 & 4.0 & 430 & 0.65 \\
\hline 16 & 6.0 & 431 & 0.73 \\
\hline 17 & 8.0 & 432 & 0.87 \\
\hline 18 & 12.0 & 433 & 1.0 \\
\hline 19 & 24.0 & 433 & 1.09 \\
\hline 20 & 36.0 & 433 & 0.92 \\
\hline 21 & 48.0 & 433 & 0.87 \\
\hline
\end{tabular}

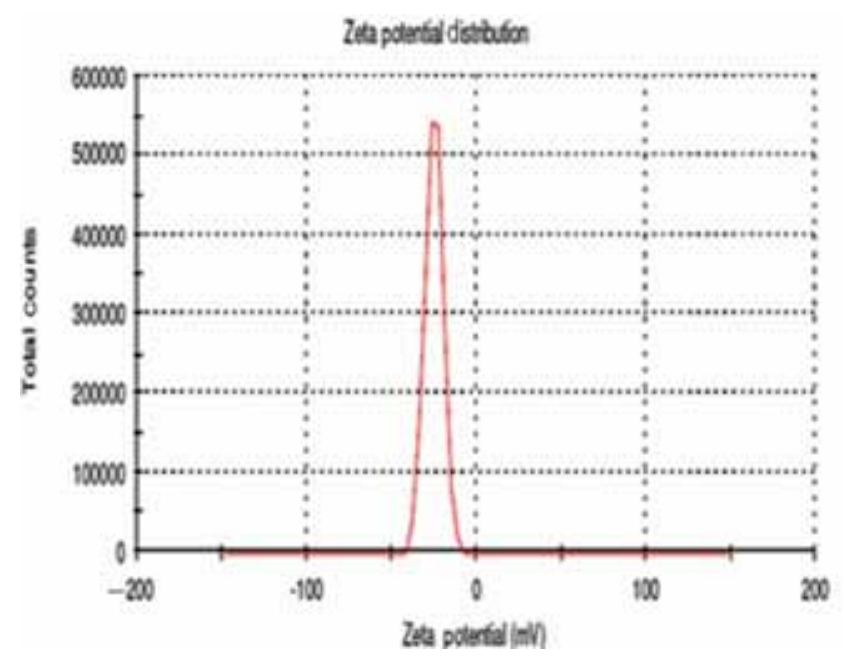

Caco-2 (human adenocarcinoma cells). Results of the present study reveals that, bioreduced AgNPs shown significant cytotoxic effects against tested in-vitro cancerous cell line models (figure 8). These results are in agreement with the earlier reports of Kaler et al. ${ }^{28}$ MCF-7 cells more susceptible to AgNPs (IC50 $5 \mu \mathrm{M})$ followed by RAW $264.7(7 \mu \mathrm{M})$ and Caco-2 cells $(10 \mu \mathrm{M})$.

\subsection{Antibacterial activity of synthesized AgNPs}

3.4a Agar well-diffusion method: The antibacterial activity of AgNPs synthesized by plant leaf extract was examined against Gram negative and Gram positive pathogenic bacteria including S. aureus, E. coli and P. aeruginosa using the agar well-diffusion method at different concentrations such as 25 , $50,75,100 \mu \mathrm{l}$ and control $(30 \mu \mathrm{l})$ (figure 9).The antibacterial effect of AgNPs was determined on the basis of zone of inhibition (mm) (table 2). Obtained results were in line with previous reports of Venkata Subbaiah and Savithramma, ${ }^{30}$ for the antimicrobial properties of AgNPs against tested pathogenic bacteria.

3.4b MIC: The MIC of the AgNPs against pathogenic bacteria is shown in table 3 . It was found that the MIC value of E. coli showed lesser activity followed by $S$. aureus and $P$. aeruginosa. The percentages of inhibition in the growth of pathogenic microorganisms in different concentrations of biosynthesized AgNPs are shown in figure 10. Present study observed results reveal that bioreduced AgNPs shows significant antibacterial property compared with positive drug control, it could be explained by their large surface area, which gives better contact with microorganisms thus alter the microbial metabolism. The nanoparticles attached to the cell membrane and penetrated inside the microorganisms. The sulphur-containing proteins were present in bacterial membrane and phosphorus-containing compounds present in DNA that was interacted with AgNPs

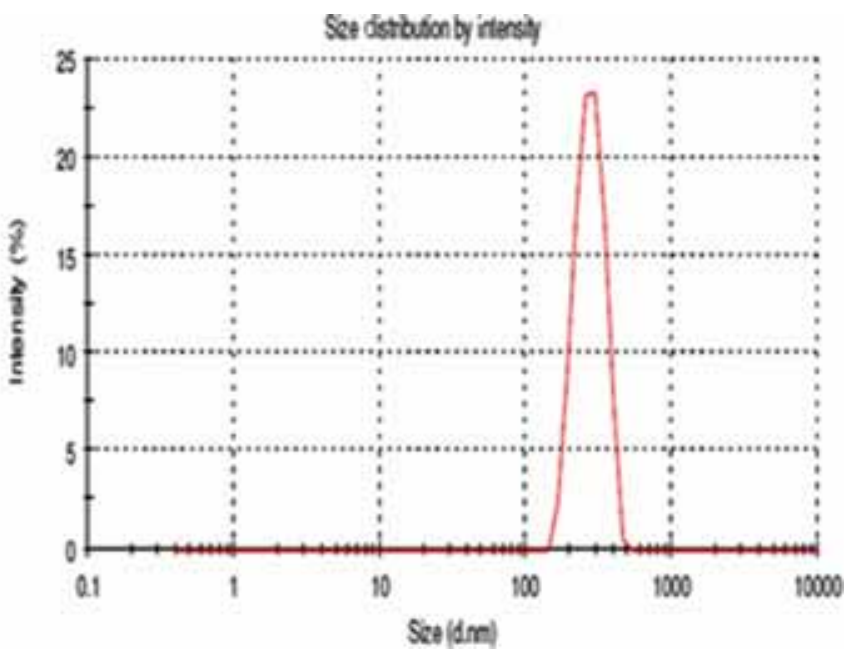

Figure 4. Dynamic light scattering analysis to determine size and zeta potential of bioreduced silver nanoparticles synthesized by $E$. alba. 
and mainly affect the respiratory chain, cell division finally leading to death. The silver ions from nanoparticles released into the bacterial cells which improved their bactericidal activity. ${ }^{31,32}$

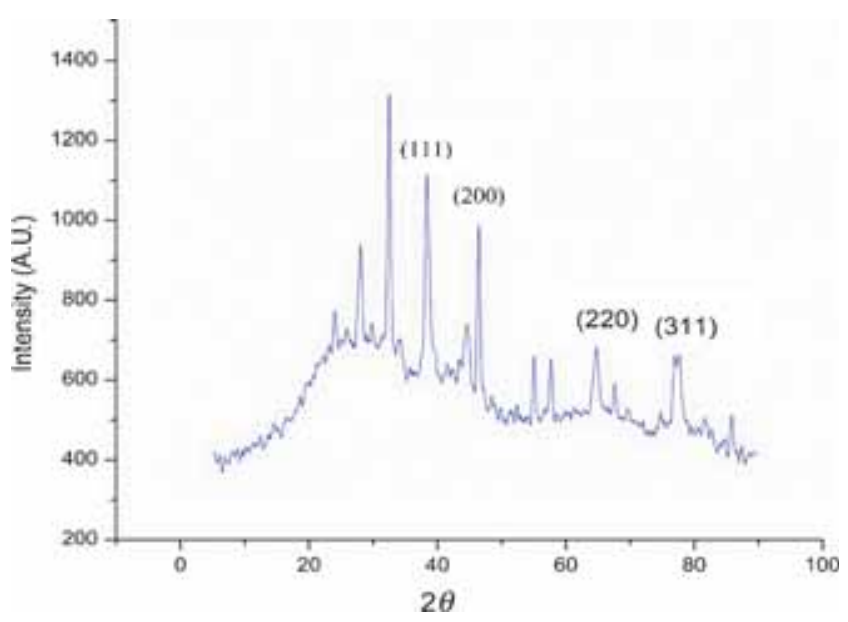

Figure 5. X-ray diffraction pattern of the bioreduced silver nanoparticles synthesized by E. alba.

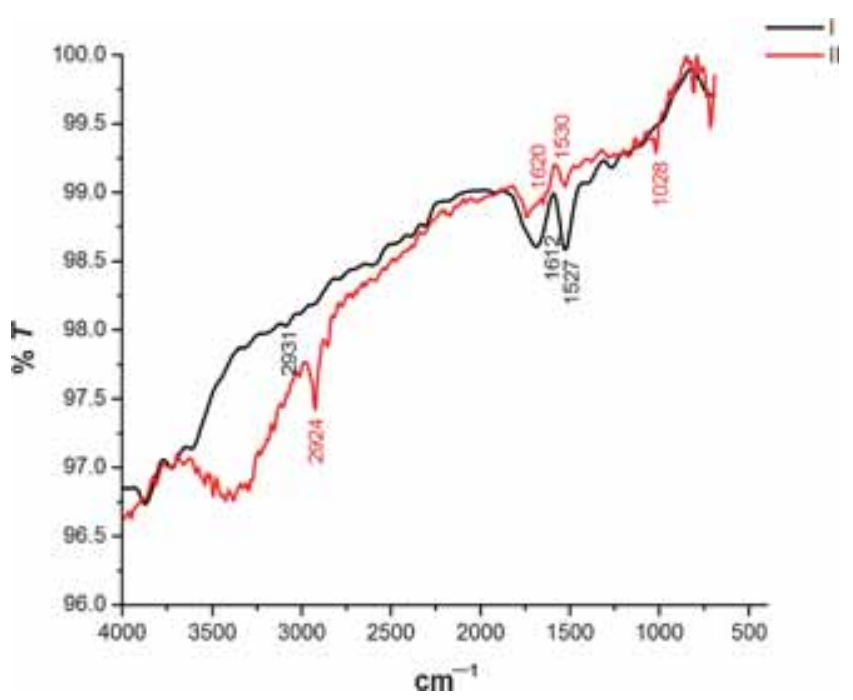

Figure 6. FT-IR analysis of bioreduced silver nanoparticles synthesized by E. alba. (I) FT-IR analysis leaf extract of E. alba and (II) silver nanoparticles of E. alba.

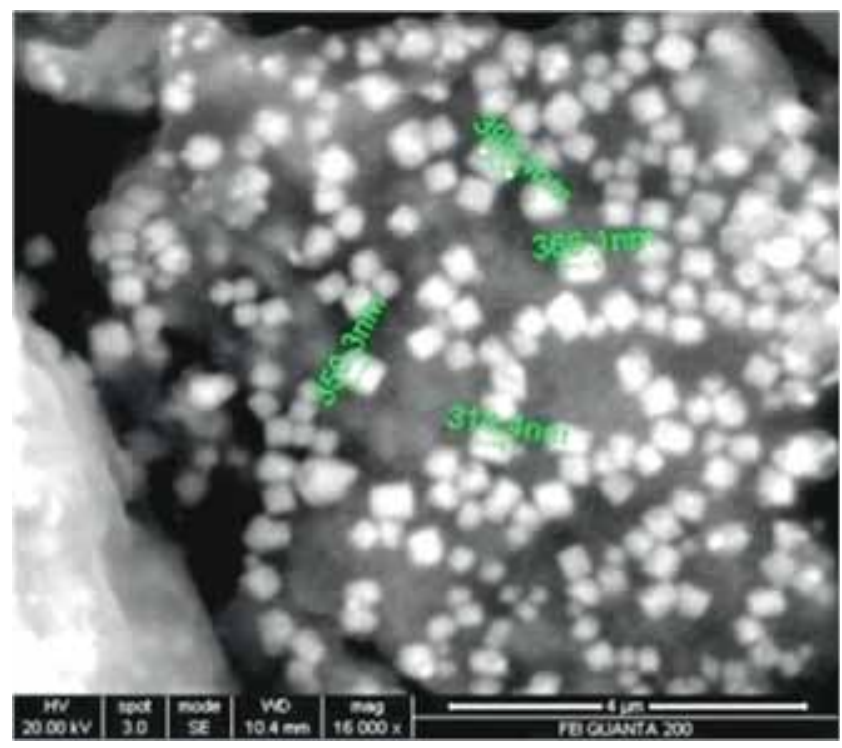

Figure 7. SEM images of bioreduced silver nanoparticles synthesized by E. alba.

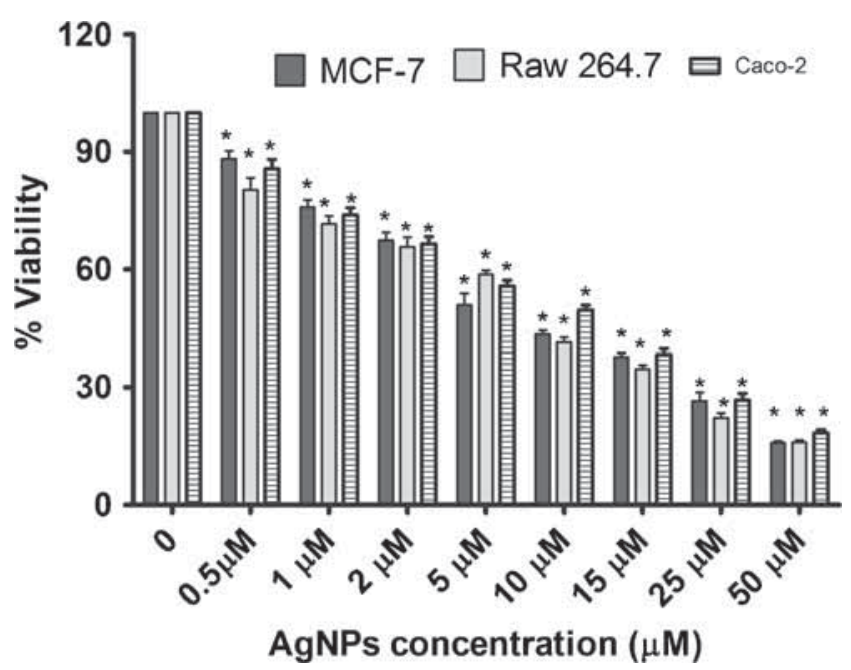

Figure 8. In-vitro cytotoxic potential of bioreduced silver nanoparticles synthesized by E. alba. MTT assay was carried out to know the anticancer activity (IC50) of the bioreduced AgNPs against MCF-7; RAW 264.7 and Caco-2 cells. Experiments were conducted in triplicates. Data are represented mean \pm SEM. ${ }^{*} p<$ 0.05 compared with controlled group, calculated by Dunetts test.

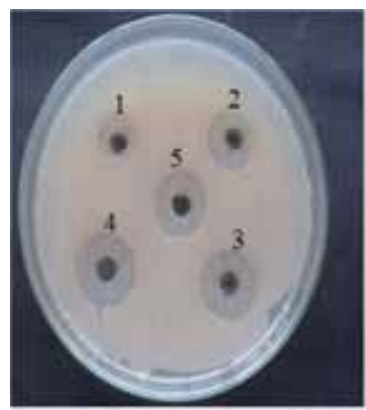

Escherichia coli

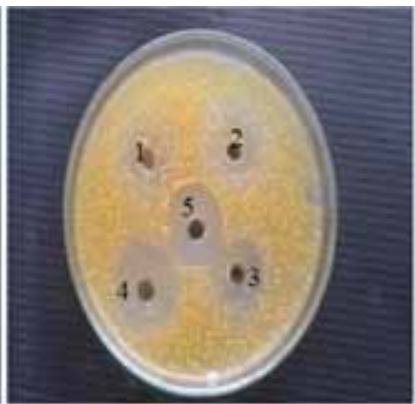

Staphylococcusaureus

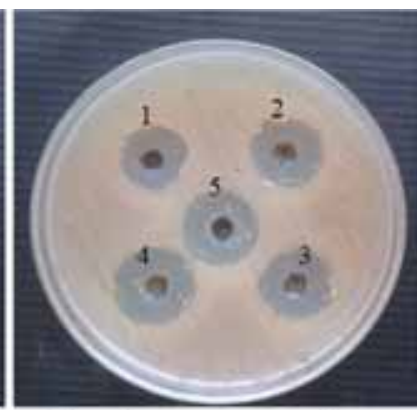

Pseudomonas aeruginosa

Figure 9. Antibacterial activity of bio-reduced silver nanoparticles synthesized by E. alba at different concentrations $1-25 \mu \mathrm{l}, 2-50 \mu \mathrm{l}, 3-75 \mu \mathrm{l}, 4-100 \mu \mathrm{l}, 5-$ control. 
Table 2. Antibacterial activity of synthesized silver nanoparticles of Eclipta alba against various microorganisms by well diffusion method.

\begin{tabular}{lccccr}
\hline & \multicolumn{5}{c}{ Zone of inhibition $(\mathrm{mm})$} \\
\cline { 2 - 6 } Pathogenic organisms & $25 \mu \mathrm{l}$ & $50 \mu \mathrm{l}$ & $75 \mu \mathrm{l}$ & $100 \mu \mathrm{l}$ & $\mathrm{C}$ \\
\hline Escherichia coli & 5 & 7 & 9 & 11 & 13 \\
Staphylococcus aureus & 8 & 10 & 11 & 13 & 15 \\
Pseudomonas aeruginosa & 7 & 9 & 11 & 12 & 13 \\
\hline
\end{tabular}

Table 3. Minimum inhibitory concentration of synthesized silver nanoparticles of Eclipta alba against various microorganisms.

\begin{tabular}{|c|c|c|c|c|c|c|c|c|c|}
\hline \multirow{2}{*}{$\begin{array}{l}\text { Pathogenic } \\
\text { microorganisms }\end{array}$} & \multirow[b]{2}{*}{ Blank } & \multicolumn{8}{|c|}{ Concentration of synthesized silver nanoparticles O.D. at $450 \mathrm{~nm}$} \\
\hline & & $10 \mu \mathrm{l}$ & $20 \mu \mathrm{l}$ & $30 \mu \mathrm{l}$ & $40 \mu \mathrm{l}$ & $50 \mu \mathrm{l}$ & $60 \mu \mathrm{l}$ & $70 \mu \mathrm{l}$ & $80 \mu 1$ \\
\hline E. coli & 1.195 & 0.982 & 0.752 & 0.642 & 0.532 & 0.419 & 0.341 & 0.252 & 0.109 \\
\hline S. aureus & 1.160 & 0.720 & 0.612 & 0.525 & 0.431 & 0.315 & 0.220 & 0.118 & 0.082 \\
\hline P. aeruginosa & 1.172 & 0.792 & 0.653 & 0.542 & 0.449 & 0.321 & 0.247 & 0.135 & 0.096 \\
\hline
\end{tabular}

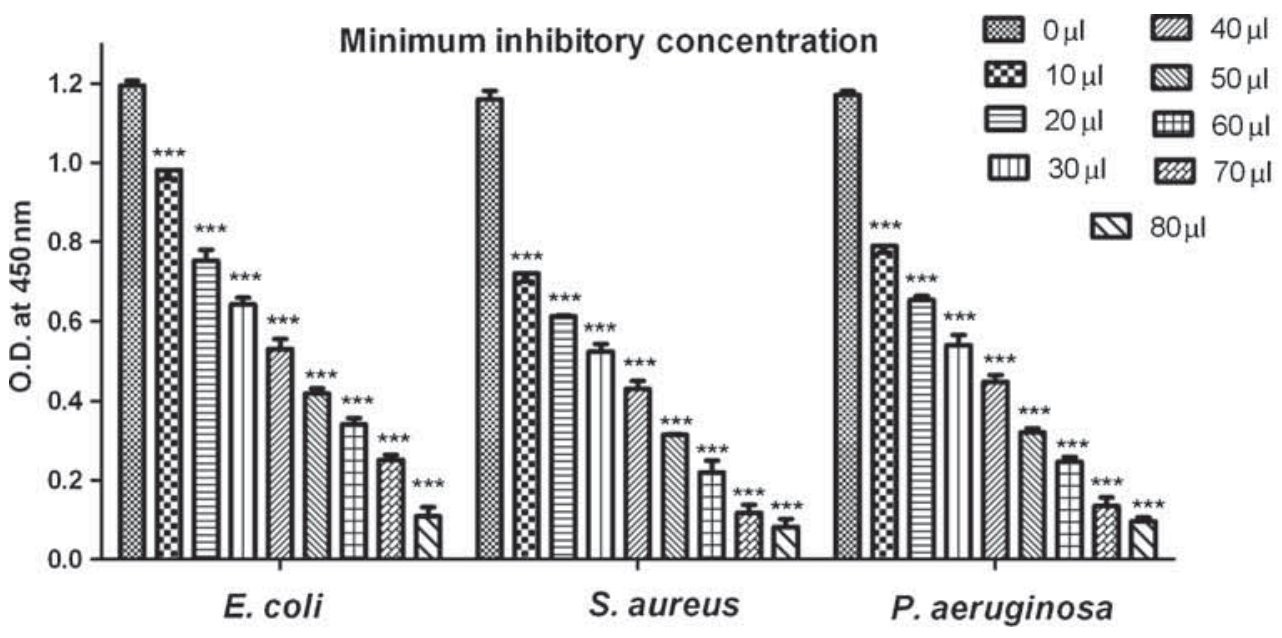

Figure 10. Minimum inhibitory concentration of bioreduced silver nanoparticles synthesized by $E$. alba against tested microorganisms. MIC test was carried out to know the minimal inhibitory concentration (MIC) of the bioreduced AgNPs against pathogenic bacterial cultures including E. coli, S. aureus and $P$. aeruginosa. Experiments were conducted in six independent replicates. Data are represented mean \pm SEM. ${ }^{* * *} p<0.001$ compared with controlled group, calculated by two-way ANOVA.

\section{Conclusion}

The present study reports the facile approach of biosynthesizing $\mathrm{AgNPs}$ from $\mathrm{AgNO}_{3}$ using the aqueous extract of $E$. $a l b a$. The adopted method is well suited with green chemistry principles as the plant extract serves as a dual functional molecule as reductant and a stabilizing agent for the synthesis of AgNPs. The efficiency and the influence of various process variables in the biosynthesis of AgNPs analysed include reductant concentration, temperature and time. The interesting conclusion arrived from the study is that the shape and size of the nanoparticles synthesized have the direct and strong influence and dependent on process variables used in the experiment. Although, highly monodispersed AgNPs were attained at concentrations $1: 9(\mathrm{~V} / \mathrm{V})$ at $32^{\circ} \mathrm{C}$ in $24 \mathrm{~h}$. The UV-visible spectra confirmed the reduction of silver ions at $433 \mathrm{~nm}$ on $24 \mathrm{~h}$ of incubation time. XRD analysis confirmed the crystalline fcc structure of AgNPs. From FTIR and $\mathrm{XRD}$ analyses it was observed that $E$. alba leaf extract acted as apparent stabilizer for the synthesis of AgNPs. The stability of the nanoparticles also recorded as stable in zeta potential estimation by DLS. The size and morphology of particles were characterized using SEM and the images showed the AgNPs in the range of 310-400 nm. Further, the biosynthesized AgNPs showed significant antibacterial action on tested pathogenic microorganisms. As a result it is observed that a fine tuning of process variables may give the end product with typical physical characteristics. 


\section{Acknowledgements}

We are thankful to the Director, and Joint Director, DRDOBU-CLS for providing necessary facilities to conduct the studies.

\section{Conflict of interest}

None.

\section{References}

1. Robert T, Morrison Robert N, Boyd and Robert K 1992 Organic chemistry, 6th edition

2. Catauro M, Raucci M G, de Gaetano F and Marotta A 2004 J. Mater. Sci: Mater. Med. 15831

3. Crabtree J H, Burchette R J, Siddiqi R A, Huen I T, Handott L L and Fishman A 2003 Peritoneal Dialysis Int. 23368

4. Krolikowska A, Kudelski A, Michota A and Bukowska J 2003 Surf. Sci. Rep. 532227

5. Zhao G J and Stevens S E 1998 Biometals 1127

6. Daniel M C and Astruc D 2004 Chem. Rev. 104293

7. Kato H 2011 Nat. Nanotechnol. 6139

8. Mittal A K, Chisti Y and Banerjee U C 2013 Biotechnol. Adv. 31346

9. Singhal G R, Bhavesh K, Kasariya A R, Sharma and Singh R P 2011 J. Nanopart. Res. 132981

10. Kim J S, Kuk E, Yu K N, Kim J H, Park S J, Lee H J, Kim S H, Park Y K, Park Y H, Hwang C Y, Kim Y K, Lee Y S, Jeong D H and Cho M H 2007 Nanomedicine: Nanotechnol. Biol. Med. 395

11. Rai M, Yadav A and Gade A 2009 Biotechnol. Adv. 2776

12. Chen S, Wu G and Zeng H 2005 Carbohydr. Polym. 6033
13. Castellano J J, Shafii S M, Ko F, Donate G, Wright T E, Mannari R J, Payne W G, Smith D J and Robson M C 2007 Int. Wound J. 4114

14. Jung R, Kim Y, Kim H S and Jin H J 2009 J. Biomater. Sci. Polym. Ed. 20311

15. Yu D G 2007 Colloids Surf. B: Biointerfaces 59171

16. Liu Y C and Lin L N 2004 Electrochem. Commun. 61163

17. Mallick K, Witcombb M J and Scurrella M S 2005 Mater. Chem. Phys. 90221

18. Nayak R R, Pradhan N, Behera D, Pradhan K M, Mishra S, Sukla L B and Mishra B K 2011 J. Nanopart. Res. 133129

19. Pattabi M and Uchil J 2000 Sol. Energy Mater. Sol. Cell 63309

20. Lin C Y C, Jacob D J, Munger J W and Fiore A M 2000 Geophys. Res. Lett. 273465

21. Jae Y S and Beom S K 2009 Bioprocess. Biosyst. Eng. 3279

22. Hutchison J E 2008 ACS Nano. 2395

23. Udayasoorian C, Kumar R V and Jayabalakrishnan M $2011 \mathrm{~J}$. Nanomater. Biostruct. 6537

24. Visconti A, Minervini F, Lucivera G and Gambatesa V 1991 Mycopathology 113181

25. Ingle A, Gade A, Pierrat S, Sonnichsen C and Rai M 2008 Curr. Nanosci. 4141

26. Mock J J, Barbic M, Smith D R, Shultz D A and Shultz S 2002 J. Chem. Phys. 1166755

27. Prabhu S and Poulose E K 2012 Nano Lett. 21

28. Kaler A, Jain S and Banerjee U C 2013 BioMed. Res. Int. 20138

29. Shankar S, Ahmad A and Sastry M 2003 Biotechnol. Prog. 19 1627

30. Venkata Subbaiah K P and Savithramma N 2013 Iajpr 31285

31. Sondi I and Salopek-Sondi B 2004 J. Colloid Interface Sci. 275 177

32. Morones J R, Elechiguerra J L, Camacho A, Holt K, Kouri J B, Ramirez J T and Yacaman M J 2005 J. Nanotechnol. 162346 